\title{
Diagnosis and management of non-clonal erythrocytosis remains challenging: a single centre clinical experience
}

\author{
Saša Anžej Doma ${ }^{1,2} \cdot$ Eva Drnovšek $^{1,3} \cdot$ Aleša Kristan $^{3} \cdot$ Martina Fink $^{1} \cdot$ Matjaž Sever $^{1,2} \cdot$ Helena Podgornik $^{1,4}$. \\ Tanja Belčič Mikič ${ }^{1,2} \cdot$ Nataša Debeljak ${ }^{3}$ Irena Preložnik Zupan ${ }^{1,2}$ (])
}

Received: 19 February 2021 / Accepted: 1 May 2021 / Published online: 19 May 2021

(c) The Author(s) 2021

\begin{abstract}
Erythrocytosis has a diverse background. While polycythaemia vera has well defined criteria, the diagnostic approach and management of other types of erythrocytosis are more challenging. The aim of study was to retrospectively analyse the aetiology and management of non-clonal erythrocytosis patients referred to a haematology outpatient clinic in an 8-year period using a 3-step algorithm. The first step was inclusion of patients with $\mathrm{Hb}>185 \mathrm{~g} / \mathrm{L}$ and/or $\mathrm{Hct}>0.52$ in men and $\mathrm{Hb}>165 \mathrm{~g} / \mathrm{L}$ and/or Hct $>0.48$ in women on two visits $\geq$ two months apart, thus confirming true erythrocytosis. Secondly, polycythaemia vera was excluded and secondary causes of erythrocytosis (SE) identified. Thirdly, idiopathic erythrocytosis patients (IE) were referred to next-generation sequencing for possible genetic background evaluation. Of the 116 patients, 75 (65\%) are men and 41 (35\%) women, with non-clonal erythrocytosis 34/116 (29\%) had SE, 15/116 (13\%) IE and 67/116 (58\%) stayed incompletely characterized (ICE). Patients with SE were significantly older and had significantly higher Hb and Hct compared to patients with IE. Most frequently, SE was attributed to obstructive sleep apnoea and smoking. Phlebotomies were performed in 56, 53 and $40 \%$ of patients in the SE, IE, and ICE group, respectively. Approx. $70 \%$ of patients in each group received aspirin. Thrombotic events were registered in 12, 20 and 15\% of SE, IE and ICE patients, respectively. Congenital erythrocytosis type 4 (ECYT4) was diagnosed in one patient. The study demonstrates real-life management of non-clonal erythrocytosis which could be optimized using a 3-step diagnostic algorithm.
\end{abstract}

Keywords Secondary erythrocytosis · Idiopathic erythrocytosis · Congenital erythrocytosis · Algorithm · Next-generation sequencing

\section{Introduction}

Erythrocytosis is a condition of a true increase in red cell mass (RCM), manifested by high haemoglobin $(\mathrm{Hb})$ concentration (>165 g/L in men and $>160 \mathrm{~g} / \mathrm{L}$ in women) and/

Irena Preložnik Zupan

irena.zupan@kclj.si

1 Department of Haematology, University Medical Centre Ljubljana, Zaloška 7, 1000 Ljubljana, Slovenia

2 Faculty of Medicine, University of Ljubljana, Korytkova 2, 1000 Ljubljana, Slovenia

3 Medical Centre for Molecular Biology, Institute of Biochemistry and Molecular Genetics, Faculty of Medicine, University of Ljubljana, Vrazov trg 2, 1000 Ljubljana, Slovenia

4 Faculty of Pharmacy, University of Ljubljana, Aškerčeva 7, 1000 Ljubljana, Slovenia or haematocrit (Hct) ( $>0.49$ in men and $>0.48$ in women) according to the 2016 WHO criteria for the diagnosis of polycythaemia vera [1,2]. Most authors agree that persistently elevated $\mathrm{Hb}>185 \mathrm{~g} / \mathrm{L}$ and $\mathrm{Hct}>0.52$ in men and $\mathrm{Hb}>165 \mathrm{~g} / \mathrm{L}$ and $\mathrm{Hct}>0.48$ in women with non-clonal background warrants further investigations [2-5]. Both parameters are affected by plasma volume and its reduction causes relative or false erythrocytosis. Absolute or true erythrocytosis is defined by RCM greater than $125 \%$ of predicted for age and sex [6]. Nevertheless, the knowledge of personal baseline values is of great importance for the interpretation of results $[4,5]$.

The causal diversity of erythrocytosis is wide and therefore requires complex diagnostic algorithms. It can have a primary or secondary cause, and both can have either congenital or acquired origin [2-4]. Primary erythrocytosis results from a defect in the erythroid bone marrow compartment, while secondary erythrocytosis results from 
a pathological condition outside the bone marrow, most often hypoxia or dysregulation in the oxygen-sensing pathway. The most common form of erythrocytosis is acquired secondary erythrocytosis (SE), caused by pulmonary, cardiac, or vascular disorders that lead to hypoxia or from an external cause of hypoxia [4]. The only primary cause of clonal erythrocytosis is polycythaemia vera (PV), almost always associated with a JAK2 mutation (JAK2 V617F or exon 12) [2, 4]. Genetic background is very rare in nonclonal erythrocytosis. Several mutations in nine different genes lead to eight types of congenital (familial) erythrocytosis (ECYT1-8). Mutations in the erythropoietin receptor $(E P O R)$ are indicative of congenital erythrocytosis type 1 (ECYT1). Mutations in genes involved in oxygen sensing (VHL, EGLN1, EPAS1, EPO) cause ECYT 2, 3, 4, and 5, respectively [7]. Mutations in genes that affect $\mathrm{Hb}$ oxygen affinity ( $H B B, H B A 1$, and $H B A 2, B P G M)$ cause ECYT 6, 7 and 8 , respectively $[7,8]$. Furthermore, in the majority of congenital erythrocytosis, the molecular defect is not identified [9] and many patients lack a specific diagnosis [8]. If no cause is found, the patient is diagnosed with idiopathic erythrocytosis (IE) [10].

Patient referral to the haematologist is often based on repeated complete blood count (CBC) without a thorough history, physical examination, or additional laboratory testing. It is important to be familiar with the contemporary evaluation of erythrocytosis, utilizing algorithms for efficient testing in the majority of patients in everyday clinical practice $[2-5,11]$. Whereas PV is almost always easily confirmed, other types of erythrocytosis are often less well recognized, weakly proven or even ignored [12-16].

The aim of our study was to retrospectively analyse non-clonal erythrocytosis patients from our centre medical records in an eight-year period. Furthermore, our goal was to sample out idiopathic patients for further genetic testing using next-generation sequencing (NGS) to determine possible genetic background.

\section{Patients and methods}

\section{Patients}

Patients aged 18 years or more, referred to the Haematology outpatient clinic, University Medical Centre (UMC) Ljubljana, between March 2011 and April 2019 were enrolled. Clinical data and blood counts were collected from the medical records. Men with $\mathrm{Hb}>185 \mathrm{~g} / \mathrm{L}$ and/or Hct $>0.52$ and women with $\mathrm{Hb}>165 \mathrm{~g} / \mathrm{L}$ and/or Hct $>0.48$ twice in an interval of $\geq$ two months were included. The study was approved by the National Medical Ethics Committee,
Ministry of Health of the Republic of Slovenia; approval no. 115/07/15 (0120-198/2015-4, 0120-287/2019-4).

\section{Study design}

To characterize the type of erythrocytosis in our study population, we used a three-step diagnostic algorithm. The simplified schematic version is presented in Fig. 1. In the first step, only patients with two CBC measurements more than two months apart were included, thus assuming that the erythrocytosis is true (not relative).

In the second step, we confirmed or excluded PV patients by checking JAK2 mutations (V618F and exon 12 when indicated) and serum EPO level. In patients with a subnormal EPO level and absent JAK2 mutations, bone marrow histology was performed. The diagnosis of PV was evaluated according to the 2016 WHO diagnostic criteria [17]. Variant JAK2 c.1849G > T (p.V617F) was detected by allele-specific PCR using DNA isolated from peripheral blood granulocytes as previously reported [18]. JAK2 exon 12 variants were determined by Sanger sequencing after the mutation was detected by HRM analysis [19]. Serum EPO levels were determined by Solid Phase Sandwich ELISA test (R\&D Systems, Inc., Abingdon, UK). At the same time, SE was confirmed or excluded by investigating the patient history, clinical, laboratory data, and the results of other diagnostic procedures. The following data were collected: patient's comorbidities (especially lung, heart, renal diseases), obesity, smoking, pulse oximetry, laboratory parameters (biochemistry, liver and kidney function, iron status, blood gases analysis with measurement of carboxyhaemoglobin (CO-Hb) and methaemoglobin (Met-Hb), oxygen pressure at $50 \% \mathrm{Hb}$ saturation (p50), imagining techniques, polysomnography in snoring or obese patients with suspicion of obstructive sleep apnoea (OSA). In patients who demonstrated increased iron stores the most frequent mutations in the homeostatic iron regulatory genes (HFE), namely c.845G > A (p.C282Y), c.193A > T (p.S65C), and c.187C > G (p.H63D), were determined by allele discrimination assays [20]. Haemoglobin electrophoresis was performed if congenital erythrocytosis was suspected. Treatment data with phlebotomies and antiplatelet agents and thrombotic complications were also collected from patients' medical records.

In the third step, we identified IE patients. They were further referred for genetic testing using targeted next-generation sequencing (NGS). Selected patients who signed informed consent for participation underwent a targeted gene panel analysis that covered 24 erythrocytosis-associated genes $[21,22]$. 


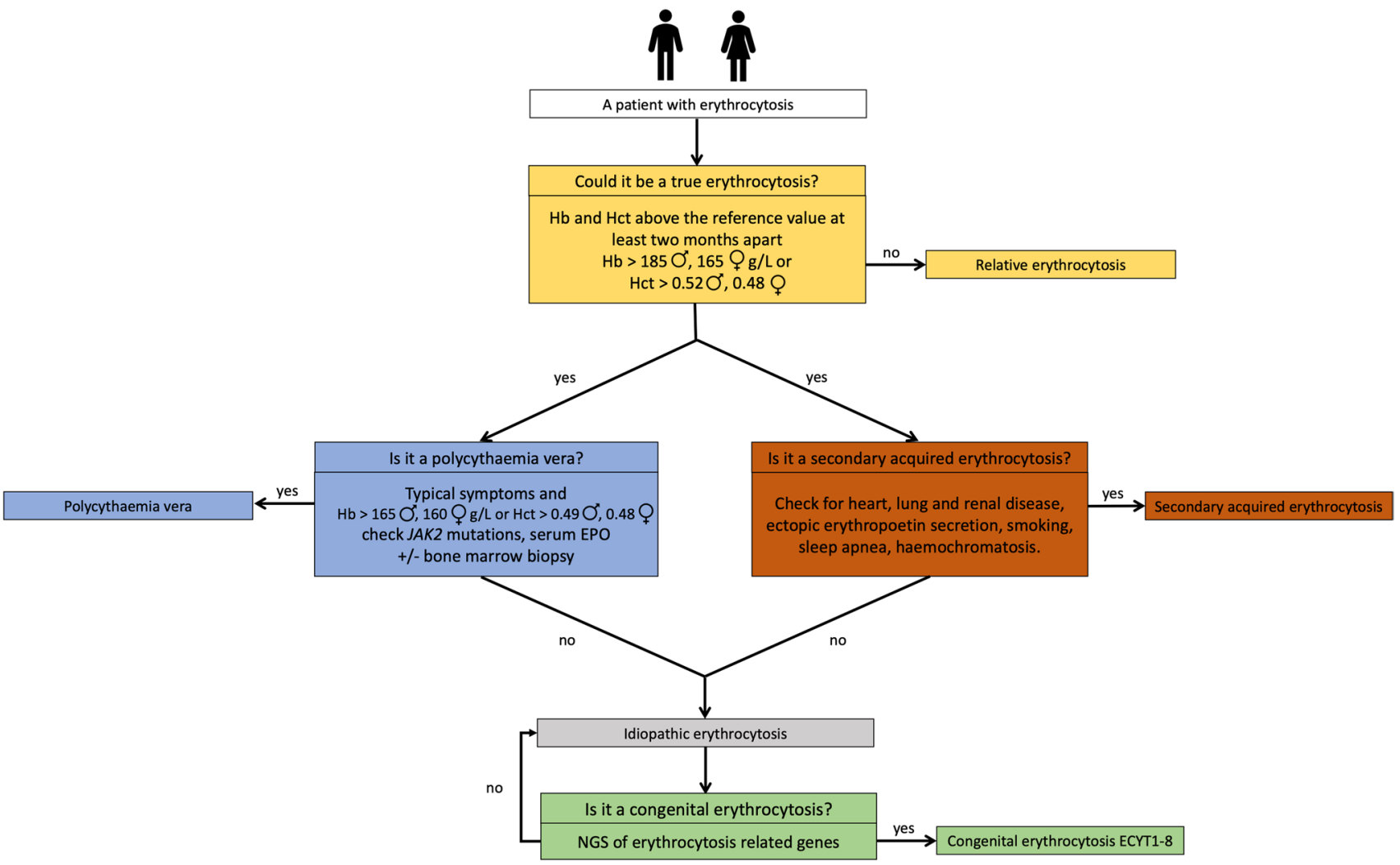

Fig. 1 Simple three-step clinical algorithm for the diagnosis of patients with erythrocytosis

\section{Statistical analysis}

In the statistical analysis, the median and interquartile range were used to describe the central tendency and variability of continuous variables. Frequencies were used to describe the distribution of categorical variables. A nonparametric Mann-Whitney test was used to compare continuous variables, while a Fisher Exact test was used to compare categorical variables. A $p$-value of $<0.05$ was considered statistically significant. Statistical analysis was performed using R Statistical Software (version 3.5.1; R Foundation for Statistical Computing, Vienna, Austria) [23].

\section{Results}

\section{Patients}

A total of 126,284 CBCs were performed in adult patients at Haematology outpatient clinic, UMC Ljubljana, between March 2011 and April 2019. Among these, 655 patients met the criteria for true erythrocytosis. The criteria for non-clonal erythrocytosis were fulfilled by 116 patients; 75 (65\%) men and 41 (35\%) women. Median age was 51.4 years (41.1-62.9) and 60.7 (54.4-68.2), in men and women, respectively. Women were significantly older than men $(p=0.002)$. Median $\mathrm{Hb}$ and Hct at diagnosis were $184 \mathrm{~g} / \mathrm{L}$ (181-192), $173 \mathrm{~g} / \mathrm{L}$ (170-180) and $0.53(0.53-0.55), 0.51(0.50-0.53)$ for men and women, respectively. There were no differences in EPO levels between men and women $(9.0(6.1-11.2)$ vs 9.9 (7.3-17.0) U/L).

\section{Patient groups}

After a complete review of the patients' medical records in $34 / 116(29 \%)$ patients a SE was determined, in 15/116 (13\%) erythrocytosis remained idiopathic (IE) despite all relevant investigations performed, but 67/116 (58\%) patients stayed incompletely characterized (ICE) as their condition did not seem clinically relevant for the treating haematologists to 
Table 1 Investigations performed/habits inquired in patients with non-clonal erythrocytosis $(\mathrm{N}=116)$

\begin{tabular}{llll}
\hline $\begin{array}{l}\text { Investigations performed/ } \\
\text { habits inquired }\end{array}$ & $\begin{array}{l}\text { Patients with investigations performed/habits } \\
\text { inquired (number/\% patients) }\end{array}$ & \multicolumn{2}{l}{ Abnormal results } \\
\cline { 3 - 4 } & & Decreased & Increased \\
\hline$J A K 2$ exon 14 V617F† & $116(100 \%) \dagger$ & $0(0 \%)$ & \\
$J A K 2$ exon $12 \dagger$ & $71(61 \%) \dagger$ & $3(0 \%)$ & $32(28 \%)$ \\
Ferritin & $112(97 \%)$ & $2(2 \%)$ & $16(14 \%)$ \\
Erythropoietin & $111(96 \%)$ & $5(5 \%)$ & $17(15 \%)$ \\
Transferrin saturation & $110(95 \%)$ & $14(19 \%)$ & - \\
Pulse oximetry & $73(63 \%)$ & $45(49 \%) *$ & \\
Smoking & $92(79 \%)$ & - & $6(25 \%)$ \\
COHb measurement & $24 / 45$ active smokers (53\%) & - & \\
Blood gas analysis & $55(47 \%)$ & - & \\
Snoring & $39(34 \%)$ & $13(76 \%) * *$ & \\
Polysomnography & $17 / 31$ patients who reported snoring (55\%) & \\
Hb electrophoresis & $14(12 \%)$ & $0(0 \%)$ & \\
p50 & $6(5 \%)$ & $0(0 \%)$ & \\
HFE & $24 / 38$ patients with increased ferritin ortrans- & $1(4 \%)$ & \\
\hline
\end{tabular}

${ }^{\dagger}$ Absent $J A K 2$ V617F mutation was an inclusion criteria. JAK2 exon 12 analysis was not mandatory, however, if determined, it had to be negative

*Active smoking; **Confirmed sleep apnea refer them to additional investigations. The investigation frequency performed and the rate of pathological results are presented in Table 1.

Exon 12 testing frequency was quite high with $61 \%$ of our patient population. More than $90 \%$ of patients had EPO, ferritin and transferrin saturation tested. Pulse oximetry was performed in only $63 \%$ and blood gas analysis in $47 \%$ of patients. Not all patients (79\%) were asked about smoking and in only $53 \%$ of active smokers $\mathrm{COHb}$ was performed. Measurement of p50 was performed in only $6(5 \%)$ patients. $34 \%$ of patients were asked about snoring. In half of them polysomnography was performed and OSA confirmed in $76 \%$. Hb electrophoresis was performed in $12 \%$ of patients.

In the majority of patients, EPO was within the normal range (3.3-16.6 IU/L), it was increased in only $14 \%$ of patients. EPO level was higher in SE group but not significantly.

Table 2 compares laboratory characteristics of our patient groups: SE, IE and ICE; patients with IE were significantly younger than patients with $\mathrm{SE}$ and had significantly lower $\mathrm{Hb}$ and Hct values than patients with SE. The tobacco abuse and different comorbidities, associated with SE in our patient population are shown in Table 3. Most frequently SE was attributed to obstructive sleep apnoa, smoking and lung diseases.

Table 2 Characteristics and differences among patients with secondary erythrocytosis (SE), idiopathic erythrocytosis (IE) and incompletely characterized erythrocytosis (ICE) $(\mathrm{N}=116)$

\begin{tabular}{|c|c|c|c|c|}
\hline \multirow[t]{2}{*}{ Laboratory characteristics } & \multicolumn{4}{|l|}{ Median (25-75\%) } \\
\hline & Patients with $S E(N=34)$ & Patients with IE $(N=15)$ & $\begin{array}{l}\boldsymbol{p} \text { value (SE } \\
\text { vs IE) }\end{array}$ & Patients with ICE $(N=67)$ \\
\hline Age (years) & $57.7(47.3-63.8)$ & $41.1(35.4-52.0)$ & 0.01 & $58.0(45.6-67.9)$ \\
\hline Male (N)/female (N) & $25 / 9$ & $12 / 3$ & 0.73 & $38 / 29$ \\
\hline Haemoglobin (g/L) & $189(182-197)$ & $182(176-183)$ & 0.02 & $180(172-185)$ \\
\hline Haematocrit & $0.55(0.53-0.58)$ & $0.52(0.52-0.53)$ & 0.002 & $0.53(0.51-0.54)$ \\
\hline Erythropoietin (IU/L) & $9.8(7.6-17.2)$ & $8.2(6.1-12.5)$ & 0.22 & $8.6(6.2-11.3)$ \\
\hline
\end{tabular}

Haemoglobin and haematocrit in the table reflect the patient's first measurement before phlebotomies. Normal range of erythropoietin is 3.316.6 IU/L 
Table 3 Diseases and habits causing secondary erythrocytosis in a group of patients with secondary erythrocytosis $(\mathrm{N}=34)$

\begin{tabular}{ll}
\hline Disease or habit & $\begin{array}{l}\text { Number and frequen- } \\
\text { cies of patients with } \\
\text { SE }\end{array}$ \\
\hline Lung disease (COPD) with saturation $<92 \%$ & $6(18 \%)$ \\
Cardiovascular disease (right-to-left cardiovascular shunts) & $2(6 \%)$ \\
Neurological disorders affecting respiratory function & $2(6 \%)$ \\
Obstructive sleep apnoea & $13(38 \%)$ \\
Active smoking with COHb $\geq 5 \%$ & $7(21 \%)$ \\
Kidney disease (RCC, renal cysts, polycystic kidney disease) & $6(12 \%)$ \\
Tumor with ectopic EPO secretion & $2(6 \%)^{*}$ \\
Hemochromatosis confirmed with Sanger sequencing & $1(3 \%)$ \\
Drugs & $2(6 \%)$ \\
\hline
\end{tabular}

Some patients had more than one possible cause

*Hemangioblastoma, unspecified frontal tumour

$S E$, secondary acquired erythrocytosis; $C O H b$, carboxyhaemoglobin; $C O P D$, chronic obstructive pulmonary disease; $E P O$, erythropoietin; $R C C$, renal cell carcinoma

\section{Treatment and thrombotic complications}

The treatment choice in selected patient groups is presented in Table 4 . About $70 \%$ of patients in all three groups received aspirin. Phlebotomies were performed at least once in 56, 53 and $40 \%$ of patients in the SE, IE and ICE group, respectively. Among 15 patients with IE, 3 (20\%) had thrombosis, whereas, in a group of 34 patients with SE, there were 4 patients $(12 \%)$ with thrombosis; between the two groups no significant differences were found. In ICE group $10 / 67$ patients $(15 \%)$ had a thrombotic event.

\section{NGS analysis results}

Among 15 patients with IE, 13 underwent NGS analysis for congenital erythrocytosis. A pathogenic variant c. $1609 \mathrm{G}>\mathrm{A}$ (p.Gly537Arg) in the EPAS1 gene, indicative of congenital erythrocytosis type 4 (ECYT4) was identified in one patient with elevated EPO levels. No other known disease-causing variants for congenital erythrocytosis were found.

\section{Discussion}

Erythrocytosis frequently represents a challenge for the physician. While PV management has been well established [24], non-clonal erythrocytosis attracts less interest in the clinical and scientific community $[12,25]$. Therefore, many $J A K 2$ negative erythrocytosis patients with erythrocytosis and with no apparent secondary cause for erythrocytosis do not have an adequate follow-up. Some haematologists even stop erythrocytosis work-up when PV is ruled out.

The three-step diagnostic algorithm, we used to retrospectively check diagnostic procedures performed in our patients, is a simple tool developed recently at our department to guide haematologists to proper erythrocytosis classification. In the first step, it reminds us which level of $\mathrm{Hb}$ and Hct warrants further investigation as well as that erythrocytosis can be relative. As RCM measurement as a gold standard for absolute erythrocytosis confirmation is not available in our centre and usually not elsewhere [26], we used two separate CBC measurements at least two months apart to confirm true erythrocytosis. Nevertheless, in the study of Johansson et al., where patients had RCM carried out, only $35 \%$ of men with $\mathrm{Hb}$ above $185 \mathrm{~g} / \mathrm{L}$ and $65 \%$ of women with $\mathrm{Hb}$ above $165 \mathrm{~g} / \mathrm{L}$

Table 4 Treatment choice in patients with non-clonal erythrocytosis $(\mathrm{N}=116)$

\begin{tabular}{lllll}
\hline & $\begin{array}{l}\text { All patients } \\
(\mathrm{N}=116)\end{array}$ & $\begin{array}{l}\text { Patients with SE } \\
(\mathrm{N}=34)\end{array}$ & $\begin{array}{l}\text { Patients with IE } \\
(\mathrm{N}=15)\end{array}$ & $\begin{array}{l}\text { Patients with incompletely char- } \\
\text { acterized erythrocytosis (N=67) }\end{array}$ \\
\hline $\begin{array}{l}\text { Phlebotomies after exclusion of PV } \\
\text { Prescribed aspirin }\end{array}$ & $54(47 \%)$ & $19(56 \%)$ & $8(53 \%)$ & $27(40 \%)$ \\
$47(70 \%)$
\end{tabular}

$P V$, polycythaemia vera; $S E$, secondary acquired erythrocytosis; $I E$, idiopathic erythrocytosis 
had absolute erythrocytosis [2, 27]. On the other hand, some patients with absolute erythrocytosis could be missed in our study due to inclusion requirement of two $\mathrm{CBC}$.

In the second step of the algorithm, clonal erythrocytosis was ruled out and secondary causes were reviewed. $J A K 2$ genetic testing was performed in all of our patients and serum EPO level in 96\%. After a thorough documentation review of all patients secondary erythrocytosis was found in 34/116 (29\%) patients, 15/116 (13\%) remained idiopathic despite adequate diagnostics, whereas a quite high number of patients, 67/116 (58\%) would need further investigations for characterisation of erythrocytosis according to modern diagnostic algorithms [2-4, 11, 28]. It seems that patients with non-clonal erythrocytosis were not considered at high risk for complications and therefore were not referred for further investigations. It also seems that haematologists are less familiar or less interested in diagnostic algorithms of non-PV erythrocytosis and/or that non-clonal erythrocytosis is often trivialized $[12,25]$.

Fourteen percent of our patients had increased serum EPO which distinguishes secondary from primary erythrocytosis $[5,8]$. The majority of patients had EPO within the normal range between 3.3 and $16.6 \mathrm{IU} / \mathrm{L}$. This is surprising, as normal EPO level is inappropriate for a raised $\mathrm{Hb}$ and Hct [2]. As expected, patients with IE had lower EPO compared to patients with SE, but differences were not significant, probably due to low numbers. Additionally, a large number of ICE patients precludes us from interpreting EPO levels. In two patients, brain tumours were found (hemangioblastoma and unspecified frontal tumour). Furthermore, in three patients renal cysts were identified. Tumours with inappropriate EPO production and secondary erythrocytosis described in the literature are cerebellar hemangioblastomas, meningiomas, pheochromocytoma, uterine leiomyomas, parathyroid adenomas, hepatocellular carcinoma, and renal cell carcinoma [4, 29]. Renal cysts are also a known cause of EPO elevation [30, 31]. Two patients with renal cell carcinoma and erythrocytosis had normal EPO levels, a surprising but not an isolated finding [32]. A patient diagnosed with ECYT4 also had elevated EPO, although that is not necessarily the case in ECYT 4 [3, 33], which can present with normal, elevated, or decreased EPO [3].

Iron deficiency may sometimes mask erythrocytosis and mislead the diagnostic procedures. Both parameters of iron stores, ferritin and transferrin saturation should be measured in hypochromia with microcytosis or reactive thrombocytosis in CBC [10, 34]. Furthermore, in iron overload patients with increased ferritin (women $\geq 150$ to $200 \mathrm{ng} / \mathrm{mL}$ and men $\geq 200$ to $300 \mathrm{ng} / \mathrm{mL}$ ) and transferrin saturation $\geq 45 \%$, genetic testing for hereditary haemochromatosis is warranted as erythrocytosis sometimes, yet rarely, appears in haemochromatosis patients [35, 36]. Among 24 patients tested for common HFE mutations using Sanger sequencing, only one patient was diagnosed with hereditary haemochromatosis type 1 (HFE1), thus classified as SE patient. Recently, it was reported that patients with IE had a higher incidence of heterozygous $H F E$ mutations, but possible relationship between hereditary haemochromatosis and erythrocytosis necessitates further evaluation $[37,38]$.

In $20 \%$ of our patients, smoking history was not taken, almost $40 \%$ have not had standard pulse oximetry performed and only a third were asked about snoring. As a result, fewer blood gas analyses and polysomnography testing were performed. Polysomnography is an investigation of choice when OSA is suspected. It should be performed in advanced cardiopulmonary disease, in patients with a higher likelihood of central apnoea, including those with heavy snoring, daytime somnolence, and/or increased BMI above $30 \mathrm{~kg} / \mathrm{m}^{2}$ [24]. As smoking and OSA are the two most common causes of secondary erythrocytosis, also in our study group, patients would need such verification [4, 28]. P50 determination and $\mathrm{Hb}$ electrophoresis were done in 5 and $12 \%$ of our patients, respectively, with no pathological results found. If congenital erythrocytosis is suspected, p50 could be measured since it is a quick, simple, and inexpensive test done by most blood gas analysers [39]. However, the sensitivity and specificity of p50 in venous blood gases are low [40], and repetition for confirmation is indicated. With the advent of NGS and much broader diagnostic range available, p50 could be omitted as also suggested by others [41].

In the third step of our diagnostic algorithm, after excluding all known causes, 15 IE patients were identified. In such patients, especially those with a positive family history or erythrocytosis since childhood, Sanger sequencing of 9 genes involved in erythrocytosis can be used to assess a possible genetic background of erythrocytosis. It is known that by sequencing these nine genes only in around $30 \%$ of IE patients known pathogenic variants in causative genes for ECYT 1-8 are identified [3, 21]. NGS analysis has recently been shown to be a promising tool in finding new diseasedriven variants [21]. At our centre, neither Sanger nor NGS had been available for congenital erythrocytosis until 2019. Among 13 IE patients from our study who underwent NGS analysis, one was diagnosed with congenital erythrocytosis type 4 (ECYT 4), which is indeed a very rare disease [41], described so far in approximately 50 patients worldwide [42].

The treatment guidelines for non-clonal erythrocytosis are not clear $[24,26]$. This is in contrast with PV, where maintenance of Hct below 0.45 with phlebotomies, antiplatelet drugs, and cytoreduction in high-risk patients are the mainstays of treatment. As demonstrated in Table 4, phlebotomies were performed in $56 \%, 53 \%$ and $40 \%$ of our patients in SE, IE and ICE group, respectively. Approximately $70 \%$ of patients in all three groups were prescribed aspirin. Thrombotic events were documented in 12, 20 and $15 \%$ of SE, IE and ICE patients, respectively. British Society for Haematology guidelines for SE suggests that 
phlebotomy should be considered in patients with a recent thrombotic event, additional risk factors for thrombosis, or Hct higher than 0.56 [41, 43]. As erythrocytosis is a compensatory mechanism in these patients, the benefits and potential harms of phlebotomies should be considered [2]. Treatment decisions in our study group were made on a case-by-case basis, after an individualized risk-benefit assessment and depending on the physician's belief. Rumi et al. reached a similar conclusion [26]. The main focus in non-clonal erythrocytosis, especially SE, should be identification of the cause and specific management, including discontinuation of a poor lifestyle habit such as smoking [43]. Randi et al. demonstrated that in a larger cohort of 78 patients with IE, 37 (47\%) and $43(55 \%)$ of the patients were treated with phlebotomies and aspirin, respectively [25]. According to British guidelines, patients with IE should be prescribed aspirin according to their cardiovascular risk factors, while phlebotomies can be used only in selected cases, but no target Hct is proven optimal [41]. Patients with congenital erythrocytosis differ in their need for phlebotomies. For instance, in patients with increased oxygen affinity hemoglobinopathies (ECYT 6, 7, 8), erythrocytosis is a compensatory mechanism, and phlebotomies could be harmful [8]. All in all, the type of congenital erythrocytosis, history of thromboembolic events, patients' symptoms, and their alleviation after the procedure should be taken into consideration when deciding for phlebotomies [41].

In conclusion, our retrospective study gives us insight into a real life management of patients with non-clonal erythrocytosis. A large proportion of our patients remained inadequately characterized and consequently very likely insufficiently managed. We showed that thrombosis is not a rare event even in patients with non-clonal erythrocytosis. Also, diagnosing a neoplasm causing non-clonal erythrocytosis should always be considered. The three-step algorithm is a useful tool for everyday clinical evaluation of erythrocytosis. Secondary causes of erythrocytosis should be systematically checked and IE patients referred for genetic testing. Only patients with known aetiology of erythrocytosis can be properly managed.

\begin{abstract}
Author contribution SAD and ED contributed equally to this work. All authors whose names appear on the submission made substantial contributions to the conception, analysis and interpretation of data in the work. All authors approved the version to be published.
\end{abstract}

Funding Javna Agencija za Raziskovalno Dejavnost RS, Grant/Award Number: L3-9279 and P1-0390; University Medical Centre Ljubljana, Grant/Award Number: 20170073 and 20200231.

Data and materials availability The data that support the findings of this study are available from the corresponding author upon reasonable request.

Code availability Not applicable.

\section{Declarations}

Ethics approval and consent to participate The study was approved by the National Medical Ethics Committee, Ministry of Health of the Republic of Slovenia; approval no. 115/07/15 (0120-198/2015-4, 0120-287/2019-4). All patients enrolled in NGS analysis signed informed consent.

Consent for publication All patients enrolled in NGS analysis signed informed consent.

Conflict of interest There are no financial or other relations that could reasonably represent a conflict of interest.

Open Access This article is licensed under a Creative Commons Attribution 4.0 International License, which permits use, sharing, adaptation, distribution and reproduction in any medium or format, as long as you give appropriate credit to the original author(s) and the source, provide a link to the Creative Commons licence, and indicate if changes were made. The images or other third party material in this article are included in the article's Creative Commons licence, unless indicated otherwise in a credit line to the material. If material is not included in the article's Creative Commons licence and your intended use is not permitted by statutory regulation or exceeds the permitted use, you will need to obtain permission directly from the copyright holder. To view a copy of this licence, visit http://creativecommons.org/licenses/by/4.0/.

\section{References}

1. Arber DA, Orazi A, Hasserjian R, Thiele J, Borowitz MJ, Le Beau MM, Bloomfield CD, Cazzola M, Vardiman JW (2016) The 2016 revision to the World Health Organization classification of myeloid neoplasms and acute leukemia. Blood 127(20):2391-2405. https://doi.org/10.1182/ blood-2016-03-643544

2. McMullin MF (2016) Investigation and management of erythrocytosis. Curr Hematol Malig Rep 11(5):342-347. https://doi. org/10.1007/s11899-016-0334-1

3. Bento C (2018) Genetic basis of congenital erythrocytosis. Int J Lab Hematol 40(Suppl 1):62-67. https://doi.org/10.1111/ijlh.12828

4. Patnaik MM, Tefferi A (2009) The complete evaluation of erythrocytosis: congenital and acquired. Leukemia 23(5):834-844. https://doi.org/10. 1038/leu.2009.54

5. Tefferi A Diagnostic approach to the patient with polycythemia. In: Post T (ed). UpToDate. Waltham: UpToDate (Accessed on Dec 10, 2020)

6. Pearson TC, Guthrie DL, Simpson J, Chinn S, Barosi G, Ferrant A, Lewis SM, Najean Y (1995) Interpretation of measured red cell mass and plasma volume in adults: Expert Panel on Radionuclides of the International Council for Standardization in Haematology. Br J Haematol 89(4):748-756. https://doi.org/ 10.1111/j.1365-2141.1995.tb08411.x

7. Bento C, Cario H, Gardie B, Hermouet S, McMullin MF (2015) Congenital Erythrocytosis and Hereditary Trombocytosis Clinical presentation, diagnosis, treatment and follow-up: a practical guide with clinical cases. In. pp 9-127

8. McMullin MF (2016) Congenital erythrocytosis. Int J Lab Hematol 38(Suppl 1):59-65. https://doi.org/10.1111/ijlh.12506

9. Bento C, Almeida H, Maia TM, Relvas L, Oliveira AC, Rossi C, Girodon F, Fernandez-Lago C, Aguado-Diaz A, Fraga C, Costa RM, Araújo AL, Silva J, Vitória H, Miguel N, Silveira MP, Martin-Nuñez G, Ribeiro ML (2013) Molecular study of congenital erythrocytosis in 70 unrelated patients revealed a potential causal mutation in less than half of the cases (Where 
is/are the missing gene(s)?). Eur J Haematol 91(4):361-368. https://doi.org/10.1111/ejh.12170

10. Keohane C, McMullin MF, Harrison C (2013) The diagnosis and management of erythrocytosis. BMJ 347:f6667. https://doi. org/10.1136/bmj.f6667

11. Oliveira JL (2019) Algorithmic evaluation of hereditary erythrocytosis: pathways and caveats. Int J Lab Hematol 41(Suppl 1):89-94. https://doi.org/10.1111/ijlh.13019

12. Desnoyers A, Pavic M, Houle PM, Castilloux JF, Beauregard P, Delisle L, Le Blanc R, Dufresne J, Boisjoly JA, Ethier V (2018) Retrospective study of high hemoglobin levels in 56 young adults. J Hematol 7(2):43-50. https://doi.org/10.14740/ jh375w

13. McMullin MF (2009) Idiopathic erythrocytosis: a disappearing entity. Hematol Am Soc Hematol Educ Program 629-635. https://doi.org/10.1182/asheducation-2009.1.629

14. Finazzi G, Gregg XT, Barbui T, Prchal JT (2006) Idiopathic erythrocytosis and other non-clonal polycythemias. Best Pract Res Clin Haematol 19(3):471-482. https://doi.org/10.1016/j. beha.2005.07.006

15. McMullin MF (2012) Diagnosis and management of congenital and idiopathic erythrocytosis. Ther Adv Hematol 3(6):391-398. https://doi.org/10.1177/2040620712458947

16. McMullin MF, Bareford D, Campbell P, Green AR, Harrison C, Hunt B, Oscier D, Polkey MI, Reilly JT, Rosenthal E, Ryan K, Pearson TC, Wilkins B, General Haematology Task Force of the British Committee for Standards in H (2005) Guidelines for the diagnosis, investigation and management of polycythaemia/ erythrocytosis. Br J Haematol 130(2):174-195. https://doi.org/ 10.1111/j.1365-2141.2005.05535.x

17. Barbui T, Thiele J, Gisslinger H, Kvasnicka HM, Vannucchi AM, Guglielmelli P, Orazi A, Tefferi A (2018) The 2016 WHO classification and diagnostic criteria for myeloproliferative neoplasms: document summary and in-depth discussion. Blood Cancer $\mathrm{J}$ 8(2):15. https://doi.org/10.1038/s41408-018-0054-y

18. Baxter EJ, Scott LM, Campbell PJ, East C, Fourouclas N, Swanton S, Vassiliou GS, Bench AJ, Boyd EM, Curtin N, Scott MA, Erber WN, Green AR, Project CG (2005) Acquired mutation of the tyrosine kinase JAK2 in human myeloproliferative disorders. Lancet 365(9464):1054-1061. https://doi.org/10.1016/S01406736(05)71142-9

19. Ugo V, Tondeur S, Menot ML, Bonnin N, Le Gac G, Tonetti C, Mansat-De Mas V, Lecucq L, Kiladjian JJ, Chomienne C, Dosquet C, Parquet N, Darnige L, Porneuf M, Escoffre-Barbe M, Giraudier S, Delabesse E, Cassinat B, disorders FIoM (2010) Interlaboratory development and validation of a HRM method applied to the detection of JAK2 exon 12 mutations in polycythemia vera patients. PLoS ONE 5(1):e8893. https://doi.org/10.1371/journal. pone. 0008893

20. Le Gac G, Férec C (2005) The molecular genetics of haemochromatosis. Eur J Hum Genet 13(11):1172-1185. https://doi.org/10. 1038/sj.ejhg.5201490

21. Camps C, Petousi N, Bento C, Cario H, Copley RR, McMullin MF, van Wijk R, Ratcliffe PJ, Robbins PA, Taylor JC, Consortium W (2016) Gene panel sequencing improves the diagnostic workup of patients with idiopathic erythrocytosis and identifies new mutations. Haematologica 101(11):1306-1318. https://doi.org/10. 3324/haematol.2016.144063

22. Kristan A, Gaspersic J, Rezen T, Kunej T, Kolic R, Vuga A, Fink M, Zula S, Anzej Doma S, Preloznik Zupan I, Pajic T, Podgornik H, Debeljak N (2021) Genetic analysis of 39 erythrocytosis and hereditary hemochromatosis-associated genes in the Slovenian family with idiopathic erythrocytosis. J Clin Lab Anal 00:e23715. https://doi.org/10.1002/jcla.23715
23. R Core Team (2017) R: A language and environment for statistical computing. Vienna: R Foundation for Statistical Computing

24. McMullin MF, Harrison CN, Ali S, Cargo C, Chen F, Ewing J, Garg M, Godfrey A, S SK, McLornan DP, Nangalia J, Sekhar M, Wadelin F, Mead AJ, Committee B (2019) A guideline for the diagnosis and management of polycythaemia vera. A British Society for Haematology Guideline. Br J Haematol 184(2):176-191. https://doi.org/10.1111/bjh.15648

25. Randi ML, Bertozzi I, Cosi E, Santarossa C, Peroni E, Fabris F (2016) Idiopathic erythrocytosis: a study of a large cohort with a long follow-up. Ann Hematol 95(2):233-237. https://doi.org/10. 1007/s00277-015-2548-Z

26. Rumi E, McMullin MF, Harrison C, Ellis MH, Barzilai M, Sarid N, Mesa R, Paoli C, Angona A, Sant'Antonio E, Ferretti VV, Cavalloni C, Casetti IC, Trotti C, Barbui T (2019) Facing erythrocytosis: results of an international physician survey. Am J Hematol 94(9):E225-E227. https://doi.org/10.1002/ajh.25545

27. Johansson PL, Safai-Kutti S, Kutti J (2005) An elevated venous haemoglobin concentration cannot be used as a surrogate marker for absolute erythrocytosis: a study of patients with polycythaemia vera and apparent polycythaemia. Br J Haematol 129(5):701-705. https://doi.org/10.1111/j.1365-2141.2005.05517.x

28. Djulbegovic M, Dugdale LS, Lee AI (2018) Evaluation of polycythemia: a teachable moment. JAMA Intern Med 178(1):128130. https://doi.org/10.1001/jamainternmed.2017.6213

29. Franek E, Kokot F, Wiecek A, Pawłowski W, Myrta J, Szewczyk W, Bar A (1994) Erythropoietin concentration in cyst fluid in patients with simple renal cysts. Nephron 67(4):431-435. https:// doi.org/10.1159/000188017

30. Eckardt KU, Möllmann M, Neumann R, Brunkhorst R, Burger HU, Lonnemann G, Scholz H, Keusch G, Buchholz B, Frei U (1989) Erythropoietin in polycystic kidneys. J Clin Invest 84(4):1160-1166. https://doi.org/10.1172/JCI114280

31. Ito K, Asano T, Tominaga S, Yoshii H, Sawazaki H (2014) Erythropoietin production in renal cell carcinoma and renal cysts in autosomal dominant polycystic kidney disease in a chronic dialysis patient with polycythemia: a case report. Oncol Lett 8(5):2032-2036. https://doi.org/10.3892/ol.2014.2469

32. Kopel J, Sharma P, Warriach I, Swarup S (2019) Polycythemia with renal cell carcinoma and normal erythropoietin level. Case Rep Urol 2019:3792514. https://doi.org/10.1155/2019/3792514

33. Oliveira JL, Coon LM, Frederick LA, Hein M, Swanson KC, Savedra ME, Porter TR, Patnaik MM, Tefferi A, Pardanani A, Grebe SK, Viswanatha DS, Hoyer JD (2018) Genotype-phenotype correlation of hereditary erythrocytosis mutations, a single center experience. Am J Hematol. https://doi.org/10.1002/ajh.25150

34. Lee G, Arcasoy MO (2015) The clinical and laboratory evaluation of the patient with erythrocytosis. Eur J Intern Med 26(5):297302. https://doi.org/10.1016/j.ejim.2015.03.007

35. Raphael B, Cooperberg AA, Niloff P (1979) The triad of hemochromatosis, hepatoma and erythrocytosis. Cancer 43(2):690-694. https://doi.org/10.1002/1097-0142(197902)43:2\%3c690::aidcncr2820430241\%3e3.0.co;2-r

36. Bacon BR Clinical manifestations and diagnosis of hereditary hemochromatosis. In: Post T (ed). UpToDate, UpToDate, Waltham, MA. (Accessed on Dec 10, 2020)

37. Biagetti G, Catherwood M, Robson N, Bertozzi I, Cosi E, McMullin MF, Randi ML (2018) HFE mutations in idiopathic erythrocytosis. Br J Haematol 181(2):270-272. https://doi.org/10.1111/ bjh. 14555

38. Burlet B, Bourgeois V, Buriller C, Aral B, Airaud F, Garrec C, Bézieau S, Gardie B, Girodon F (2019) High HFE mutation incidence in idiopathic erythrocytosis. Br J Haematol 185(4):794795. https://doi.org/10.1111/bjh.15631 
39. Mangin O (2017) High oxygen affinity hemoglobins. Rev Med Interne 38(2):106-112. https://doi.org/10.1016/j.revmed.2016.06. 003

40. Huber FL, Latshang TD, Goede JS, Bloch KE (2013) Does venous blood gas analysis provide accurate estimates of hemoglobin oxygen affinity? Ann Hematol 92(4):517-521. https://doi.org/10. 1007/s00277-012-1667-z

41. McMullin MF, Mead AJ, Ali S, Cargo C, Chen F, Ewing J, Garg M, Godfrey A, Knapper S, McLornan DP, Nangalia J, Sekhar M, Wadelin F, Harrison CN, British Society for Haematology G (2019) A guideline for the management of specific situations in polycythaemia vera and secondary erythrocytosis: a British Society for Haematology Guideline. Br J Haematol 184(2):161-175. https://doi.org/10.1111/bjh.15647
42. Kristan A, Debeljak N, Kunej T (2019) Genetic variability of hypoxia-inducible factor alpha (HIFA) genes in familial erythrocytosis: analysis of the literature and genome databases. Eur J Haematol 103(4):287-299. https://doi.org/10.1111/ejh.13304

43. McMullin MF (2014) Secondary erythrocytosis. Hematology 19(3):183-184. https://doi.org/10.1179/1024533214Z.00000 0000263

Publisher's note Springer Nature remains neutral with regard to jurisdictional claims in published maps and institutional affiliations. 